INFLAMMATORY BOWEL DISEASE

\title{
Divergent cell cycle kinetics underlie the distinct functional capacity of mucosal T cells in Crohn's disease and ulcerative colitis
}

\author{
A Sturm, A Z A Leite, S Danese, K A Krivacic, G A West, S Mohr, J W Jacobberger, C Fiocchi
}

See end of article for

authors' affiliations

Gut 2004;53:1624-1631. doi: 10.1136/gut.2003.033613

Correspondence to:

Dr C Fiocchi, Division of

Gastroenterology,

University Hospitals of

Cleveland, Case Western

Reserve University School

of Medicine (BRB 425)

10900 Euclid Ave,

Cleveland, Ohio, 44106-

4952, USA;

cxf18@po.cwru.edu

Revised version received 26 February 2004

Accepted for publication

3 March 2004

\begin{abstract}
Background: Different abnormalities of T cell effector function distinguish Crohn's disease (CD) from ulcerative colitis (UC). Because cell cycling determines effector function, pathogenic events in CD and UC may depend on cell cycle changes unique to each condition.

Methods: Cell cycle kinetics, cycle regulatory molecule expression, apoptosis, caspase and telomerase activity, and cellular expansion were evaluated in CD2 and CD3 activated control, CD, and UC lamina propria T cells.

Results: Compared with normal cells, CD T cells cycle faster, express increased phosphorylated Rb and decreased phosphorylated p53 levels, display less caspase activity but more telomerase activity, die less, and undergo vigorous cellular expansion. In contrast, UC T cells cycle slower, express normal levels of phosphorylated $\mathrm{Rb}$ and $\mathrm{p} 53$, display more caspase activity but have no telomerase activity, die more, and have a limited capacity to expand.

Conclusions: T cell cycle abnormalities in CD indicate a state of hyperreactivity compatible with loss of tolerance, but a hyporeactive state compatible with anergy in UC. Thus distinct and divergent T cell cycle characteristics underlie the pathogenesis of the two main forms of inflammatory bowel disease.
\end{abstract}

$\mathrm{B}$ oth forms of inflammatory bowel disease (IBD) are characterised by chronic tissue damage mediated by disregulated mucosal T cell function. ${ }^{1}$ Although Crohn's disease (CD) and ulcerative colitis (UC) share several clinical features, the mechanisms of tissue injury may differ in each condition, ${ }^{2}$ implying that $\mathrm{T}$ cell effector function is distinct in $\mathrm{CD}$ and UC. Mucosal T cells proliferate more, express higher levels of interleukin (IL)-2 receptor $\alpha$, and are more cytotoxic in CD than UC. ${ }^{3-5}$ Production of IL-2 and interferon (IFN) $-\gamma$ is greater by CD than UC T cells, ${ }^{6-9}$ and IL-12 and IL-18 are elevated in CD but not in UC intestine. ${ }^{10-13}$ In addition, CD T cells are resistant while UC cells are susceptible to IL-4 mediated suppression. ${ }^{14}$ In addition, mucosal $\mathrm{T}$ cells express higher levels of Fas ligand in UC than in $\mathrm{CD}^{15}$ while CD T cells are more resistant to apoptosis induced by a variety of stimuli and display decreased Bax expression. ${ }^{16-18}$

These observations indicate that the pathogenic effector function of CD and UC T cells are fundamentally diverse. Effector function results from $\mathrm{T}$ cell activation which depends on the capacity to cycle in response to antigenic signals. ${ }^{19} 20$ Thus a detailed analysis of the cell cycle could reveal how $\mathrm{T}$ cell activation is regulated in normal and inflamed mucosa. Progression of $\mathrm{T}$ cells through the cell cycle is a complex process coordinated by the action of several molecules, including promoters such as cyclin dependent kinases (CDK) and inhibitors such as p21, p27, and p53. ${ }^{21}$ Cyclins bind to CDK to form regulatory complexes ${ }^{22}$ whose activity is modulated by phosphorylation and interaction with inhibitors that prevent unrestrained proliferation. ${ }^{23}{ }^{24}$ Once the signal that triggers cycling is eliminated, immune homeostasis is maintained by apoptosis, ${ }^{25-27}$ which is mediated by caspases. ${ }^{25} 28$ Finally, to allow adequate clonal expansion, proliferation also requires the activity of telomerase, a specific enzyme that preserves chromosomal length and sustains replication. ${ }^{29} 30$

The outcome of a $\mathrm{T}$ cell response depends on the balance between cell cycling and death, particularly among gut $\mathrm{T}$ cells which must maintain immune tolerance while providing protection against an antigen rich microenvironment. ${ }^{31-34}$ As tolerance seems to be lost in $\mathrm{IBD}^{32}{ }^{34}$ the mechanisms controlling cell cycling and apoptosis may be deranged leading to uncontrolled inflammation. To test this hypothesis, we performed a detailed analysis of cell cycle kinetics, evaluated expression of cell cycle regulators, measured caspase and telomerase activity, and evaluated clonal expansion of CD and UC mucosal T cells.

\section{MATERIALS AND METHODS}

\section{Reagents and antibodies}

For T cell isolation, mucosa was digested in collagenase type 3 and DNase type 1 (Worthington Biochemical Corp., Lakewood, New Jersey, USA). Human IL-2 (Chiron, Emeryville, California, USA), CD3 monoclonal antibody (mAb) (OKT3; Ortho Diagnostic System Inc., Raritan, New Jersey, USA), CD2 mAb (T112/T113; Dr Ellis Reinherz, Boston, Massachusetts, USA), CD28 mAb (ANC28.1/5D10; Ancell Corp., Bayport, Minnesota, USA), phorbol myristate acetate (PMA) (Sigma, St Louis, Missouri, USA), and phytohaemagglutinin (PHA) (Gibco, Grand Island, New York, USA) were used for $\mathrm{T}$ cell activation. Fluorescein isothiocyanate (FITC) conjugated anticyclin Bl and FITC conjugated antibromodeoxyuridine (BrdU) were from BD Pharmingen (San Diego, California, USA), rabbit antiphosphohistone $\mathrm{H} 3$ antibody from Upstate Biotechnology (Lake Placid, New York, USA), and secondary Alexa 350 conjugated

\footnotetext{
Abbreviations: CDK, cyclin dependent kinase; IBD, inflammatory bowel disease; LPT, lamina propria T cells; CD, Crohn's disease; UC, ulcerative colitis; $\mathrm{Rb}$, retinoblastoma protein; $\mathrm{BrdU}$, bromodeoxyuridine; PI, propidium iodide; CFDA SE, carboxyfluorescein diacetate succinimidyl ester; IL, interleukin; IFN, interferon; mAb, monoclonal antibody; PMA, phorbol myristate acetate; PHA, phytohaemagglutinin; FITC, fluorescein isothiocyanate; RPE, R-phycoerythrin; PBS, phosphate buffered saline; TRAP, telomeric repeat amplification protocol
} 
labelled goat antirabbit IgG from Molecular Probes (Eugene, Oregon, USA). The Vybrant carboxyfluorescein diacetate succinimidyl ester (CFDA SE) Cell Tracer Kit was from Molecular Probes and propidium iodide (PI) from Calbiochem (San Diego, California, USA). All protease and phosphatase inhibitors used for western blotting were purchased from Sigma. Antibodies against caspase 3, cyclin $\mathrm{D} 3$, retinoblastoma $(\mathrm{Rb})$ protein, cyclin $\mathrm{A}, \mathrm{p} 2 \mathrm{l}, \mathrm{p} 27$, and p53 were from BD Pharmingen. The caspase 8 antibody (StressGen Biotechnologies, Victoria, Canada) was provided by $\mathrm{Dr}$ Marc Smith (Case Western Reserve University, Cleveland, Ohio, USA) and FLIP and CDK4 antibodies were from Santa Cruz Biotechnology (Santa Cruz, California, USA).

\section{Cell isolation, induction of mucosal T cell cycling, and} proliferation assay

Intestinal $\mathrm{T}$ cells were isolated from surgical specimens from patients with $\mathrm{CD}, \mathrm{UC}$, and malignant and non-malignant conditions that provided histologically normal control tissue. All patients with IBD had active disease, as defined by the Harvey-Bradshaw activity index and the clinical colitis activity index. Specimens were obtained from $10 \mathrm{CD}$, nine UC, and 10 control patients. Patients with CD (four men and six women, aged 26-65 years) had ileocolic or colonic disease which had been present for 2-30 years. At the time of resection, four patients were receiving corticosteroids only, one corticosteroids and aminosalicylates, three 6-mercaptopurine and aminosalicylates, and two non-specific therapy. No patient was receiving infliximab therapy. Patients with UC (five men and four women, aged 24-49 years) had disease which had been present for $1-26$ years. At the time of colectomy, two patients were receiving corticosteroids only, three corticosteroids and aminosalicylates, two aminosalicylates only, and two 6-mercaptopurine and aminosalicylates. Control patients (six men and four women, aged 1877 years) included six colonic adenocarcinomas, two benign caecal polyps, one familial polyposis, and one diverticular disease. Histologically normal tissue was obtained at least $10 \mathrm{~cm}$ from the tumour, polyps, or diverticula. All diagnoses were confirmed by clinical, radiological, endoscopic, and histological criteria. The project was approved by the Institutional Review Board of University Hospitals of Cleveland. All lamina propria T cells (LPT) were isolated from colonic specimens, as previously described, ${ }^{16}{ }^{35}$ cultured in RPMI 1640, and stimulated with $1 \mathrm{ng} / \mathrm{ml} \mathrm{PMA} \mathrm{and} 0.02 \%$

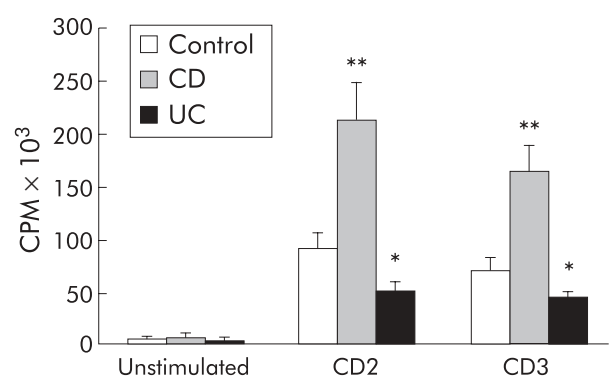

Figure 1 Distinct thymidine incorporation rate of control and inflammatory bowel disease mucosal T cells in response to receptor activation. Proliferation of Crohn's disease (CD) lamina propria T cells (LPT) was significantly greater, and that of ulcerative colitis (UC) LPT significantly lower, than that of control LPT. Cells were cultured in the absence and presence of $\mathrm{CD} 2\left(\mathrm{Tl}_{2} / \mathrm{Tl}_{1}\right)$ antibody or crosslinked anti$\mathrm{CD} 3$ monoclonal antibody for 72 hours, and pulsed with ${ }^{3} \mathrm{H}$ thymidine for the last 18 hours prior to harvesting and counting in a $\beta$-scintillation counter. Data are expressed as mean (SEM) of six separate experiments. $C P M$, counts per minute. ${ }^{*} p<0.05,{ }^{* *} p<0.005$ for $U C$ and $C D$ versus control LPT, respectively.
PHA. After two days, cells were washed, and cycling was induced by addition of 20 units of IL-2/ml twice weekly. After $10-14$ days, cultures contained $>95 \% \mathrm{CD}^{+},>80 \% \mathrm{CD}^{+}$, $>97 \% \mathrm{CD}^{2} 5 \mathrm{RO}^{+},>70 \% \mathrm{HLA}^{-} \mathrm{DR}^{+},<0.6 \% \mathrm{CDl} 4^{+}$, and $<0.9 \%$ $\mathrm{CD} 19^{+}$cells, regardless of their IBD or control origin and use of medications. ${ }^{16}$ To induce cycling, these $\mathrm{T}$ cells were activated by cross linked anti-CD3 mAb ( $10 \mu \mathrm{g} / \mathrm{ml})$ or soluble anti-CD2 mAb pairs (1:1000) for three days, and to measure proliferation, $0.5 \mu \mathrm{Ci}$ of $\left[{ }^{3} \mathrm{H}\right]$ thymidine/well (DuPont NEN, Boston, Massachusetts, USA) was added 18 hours before the end of culture.

\section{Flow cytometric analyses}

Cell surface staining

Cell phenotype was routinely analysed using CD3-R-phycoerythrin (RPE) conjugated mAb (Dako, Carpinteria, California, USA), and background fluorescence determined by RPE conjugated mouse IgG.

\section{Cell cycle phase distribution}

Staining for DNA content, cyclin B1, and mitotic cells was performed as previously described. ${ }^{36}$ Briefly, cells were washed in phosphate buffered saline (PBS), fixed in $90 \%$ methanol at $-20^{\circ} \mathrm{C}$, and incubated with antiphospho-histone H3, followed by Alexa 35 conjugated goat-anti rabbit IgG. Cells were washed, incubated with FITC conjugated anticyclin Bl, suspended in PBS and $5 \mu \mathrm{l}$ of RNase $(0.6 \mu \mathrm{g} / \mathrm{ml}$, 30-60 Kunitz units; Sigma), incubated at $37^{\circ} \mathrm{C}$ for 15 minutes, and then chilled on ice, and PI $(200 \mu \mathrm{g} / \mathrm{ml})$ was added prior to flow cytometry.

\section{Cell cycle kinetics and potential doubling time} Cell kinetics were performed using two colour flow cytometry on cells grown for three days with or without stimulus and incubated for 60 minutes with $20 \mu \mathrm{M}$ BrdU chased with thymidine. BrdU labelled nuclei were then stained with FITC conjugated anti-BrdU and PI. Denaturation of DNA allowing antibody binding to incorporated BrdU was achieved by acid treatment. Mathematical analysis was performed according to Begg et al and White and colleagues, ${ }^{37}{ }^{38}$ and movement of BrdU labelled cells across $S$ phase relative to the position of Gl and G2+M (relative movement, RM) was calculated by the formula

$$
\mathrm{RM}(\mathrm{t})=(\mathrm{FS}(\mathrm{t})-\mathrm{FGl}(\mathrm{t})) / \mathrm{FG} 2+\mathrm{M}(\mathrm{t})-\mathrm{FGl}(\mathrm{t}))
$$

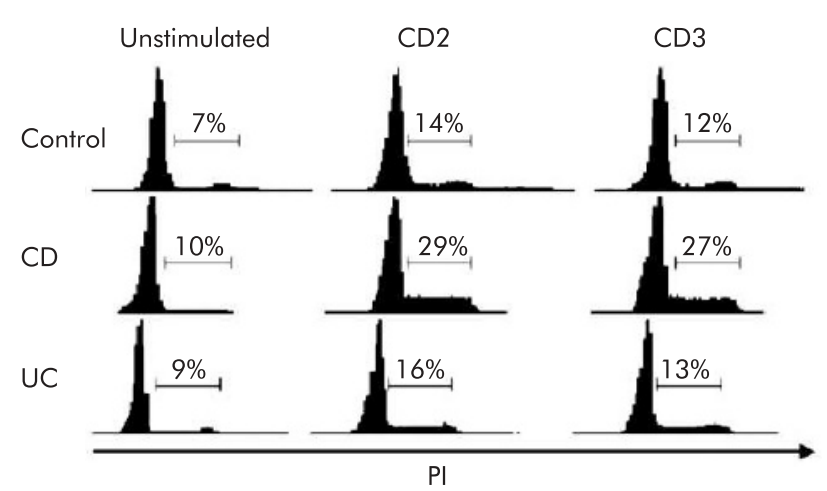

Figure 2 Distinct cell cycle phase progression of control and inflammatory bowel disease mucosal T cells in response to receptor activation. The number of Crohn's disease (CD) lamina propria T cells (LPT) in S and G2/M phase was significantly greater than that of control or ulcerative colitis (UC) LPT $(p<0.05)$, regardless of the stimulus used. Cells were cultured in the absence and presence of CD2 $\left(\mathrm{Tl}_{2} / \mathrm{T}_{1} 1_{3}\right)$ antibody or crosslinked anti-CD3 monoclonal antibody for 72 hours, and cell cycle phases were assessed by measuring DNA content by propidium iodide staining followed by flow cytometry. The graphs are representative of 7-9 different experiments. 
Table 1 Differential effect of CD2 and CD3 activation on lamina propria T cell (LPT) cell cycle kinetics

\begin{tabular}{llllll}
\hline & $\begin{array}{l}\text { G0/G1 traverse } \\
\text { time* }\end{array}$ & $\begin{array}{l}\text { S traverse } \\
\text { time* }^{*}\end{array}$ & $\begin{array}{l}\text { G2/M traverse } \\
\text { time* }\end{array}$ & $\begin{array}{l}\text { Potential } \\
\text { doubling time } \\
\left(\mathbf{T}_{\text {pot }}\right)^{*}\end{array}$ & $\begin{array}{l}\text { Cells in mitosis } \\
(\%) \dagger\end{array}$ \\
\hline Control anti-CD2 & $8.5(0.9)$ & $25.8(3.0)$ & $7.6(1.1)$ & 41.9 & $0.69(0.07)$ \\
Control anti-CD3 & $8.1(1.1)$ & $30.5(3.2)$ & $6.3(0.6)$ & 44.9 & $0.53(0.09)$ \\
CD anti-CD2 & $6.7(0.9)$ & $13.8(1.9)$ & $5.7(0.9)$ & 26.2 & $1.31(0.16)$ \\
CD anti-CD3 & $7.1(1.1)$ & $14.9(1.3)$ & $5.4(0.7)$ & 27.4 & $1.26(0.14)$ \\
UC anti-CD2 & $7.9(0.8)$ & $31.3(2.4)$ & $6.9(1.0)$ & 46.1 & $0.49(0.04)$ \\
UC anti-CD3 & $8.8(0.9)$ & $35.4(3.5)$ & $6.8(0.8)$ & 51.0 & $0.44(0.05)$ \\
\hline \\
CD, Crohn's disease; UC, ulcerative colitis. \\
*Values represent time in hours. \\
tPercentage of phospho-histone H3 positive cells at 72 hours.
\end{tabular}

where $\mathrm{FGl}=$ unlabelled $\mathrm{Gl}$ mean red fluorescence; $\mathrm{FG} 2+\mathrm{M}=$ unlabelled $\mathrm{G} 2+\mathrm{M}$ mean red fluorescence, and $\mathrm{FS}=$ mean red fluorescence of the BrdU labelled cells at time (t). S phase duration (TS) was calculated as the time for one unit relative movement (RM). The potential doubling time was computed by the formula

$\mathrm{T} p o t=\ln (2) \mathrm{TS} / v$

with $v$ defined as $\ln \left[1+\mathrm{f}^{\mathrm{lu}}(\mathrm{t}) / \mathrm{l}-\mathrm{f}^{\mathrm{ld}}(\mathrm{t}) / 2\right]$

where $\mathrm{f}^{\mathrm{lu}}(\mathrm{t})=$ fraction of labelled undivided cells at time $(\mathrm{t})$ and $\mathrm{f}^{\mathrm{ld}}(\mathrm{t})=$ fraction of labelled divided cells at time $(\mathrm{t})$.

Analysis of cell division

Analysis of cell division was performed by dye dilution using the Vybrant CFDA SE Cell Tracer Kit according to the manufacturer's instruction. Stained cells were cultured alone or with anti-CD2 mAb pairs or crosslinked anti-CD3 mAb, each with CD28 $(5 \mu \mathrm{g} / \mathrm{ml})$ and IL-2 $(20 \mathrm{U} / \mathrm{ml})$. After four days, cells were washed in PBS, fixed with $1 \%$ paraformaldehyde, and analysed.

\section{Apoptotic index}

The percentage of apoptotic events (apoptotic index) was determined in PI stained cells by gating the sub-Gl events content in the respective histograms.
Western blotting, assessment of caspase activity, and measurement of telomerase activity

Western blotting and assessment of caspase activity were performed as previously reported..$^{39}$ Telomerase activity was measured using a photometric enzyme immunoassay (Telo TAGG Telomerase PCR ELISA; Roche-Diagnostics GmbH, Mannheim, Germany) based on the telomeric repeat ampli-

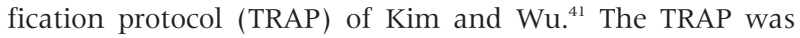
performed according to the manufacturer's instructions. ${ }^{41}$ The human kidney cell line 293 was used as a positive and heat inactivation of telomerase as a negative control.

\section{Statistical analysis}

Statistical analysis was performed using ANOVA, Student's $t$, or Mann-Whitney test. Results are expressed as mean (SEM) and significance was inferred with $\mathrm{p}$ values $<0.05$.

\section{RESULTS}

Distinct $T$ cell cycle phase distribution in CD and UC Compared with peripheral blood T cells, LPT display unique cell cycle kinetics ${ }^{40}$ and we initially investigated whether such kinetics were altered in CD or UC. Compared with control LPT, CD cells displayed significantly increased $(\mathrm{p}<0.005)$ and UC cells significantly decreased $(\mathrm{p}<0.05)^{3}[\mathrm{H}]$-thymidine

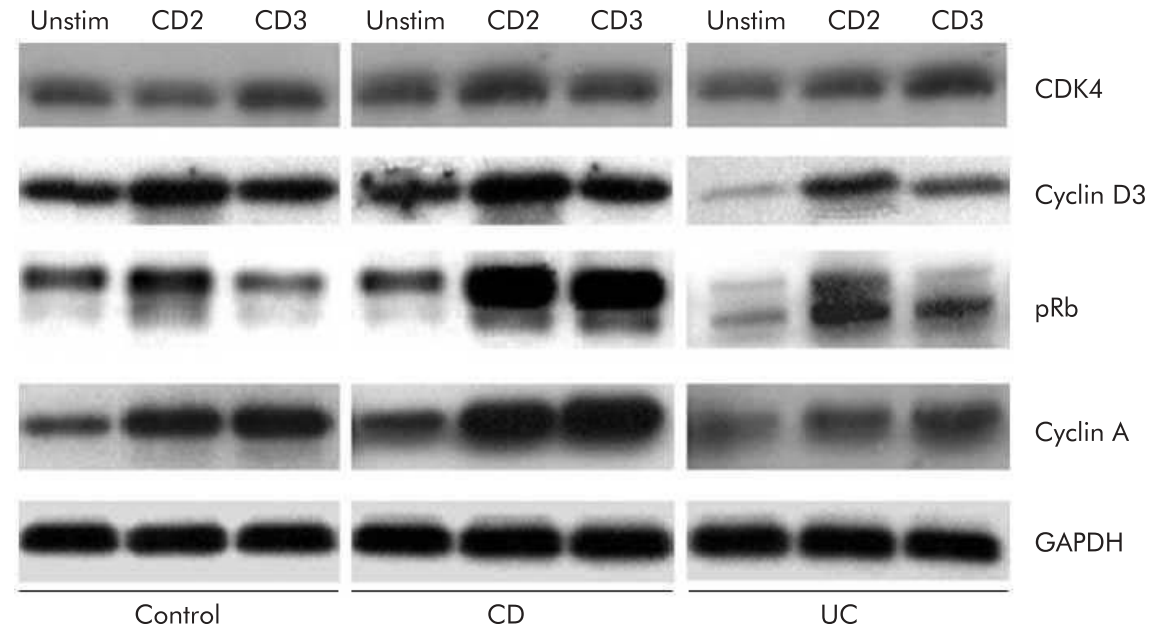

Figure 3 Differential expression of cell cycle promoters in control and inflammatory bowel disease mucosal T cells. Immunoblot analysis showed that upregulation of cyclin D3 and CDK4 was comparable in anti-CD2 or anti-CD3 activated control, Crohn's disease (CD), and ulcerative colitis (UC) lamina propria T cells (LPT). Phosphorylation of retinoblastoma protein (Rb) and expression of cyclin A were greater in CD than in control and UC LPT. Cells were cultured in the absence and presence of anti-CD2 or anti-CD3 for three days, after which expression of cell cycle promoters was assessed by western blotting. Each panel is representative of 5-8 different experiments. 


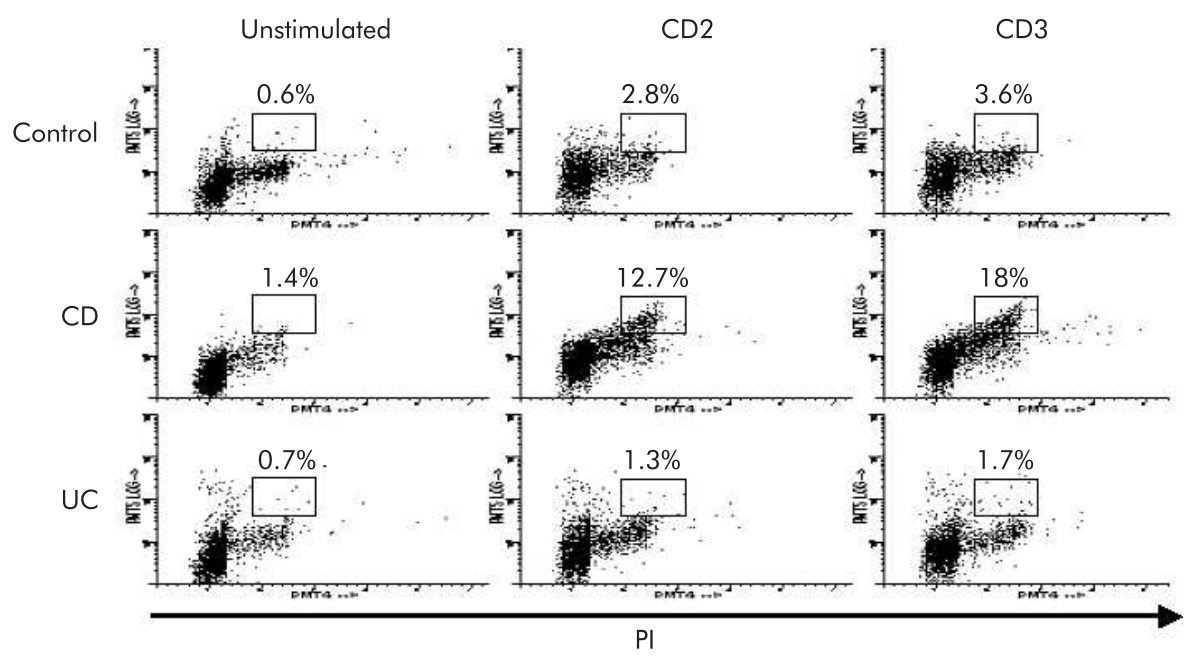

Figure 4 Differential expression of cyclin B1 in control and inflammatory bowel disease mucosal T cells.

Compared with control cells, flow cytometric analysis showed increased cyclin $\mathrm{B} 1$ expression in the $\mathrm{G} 2 / \mathrm{M}$ phase of activated Crohn's disease (CD) but lower levels in activated ulcerative colitis (UC) lamina propria T cells (LPT). Cells were cultured in the absence and presence of anti-CD2 or anti-CD3 for three days, after which cyclin B1 expression and DNA content were examined by flow cytometry. The figure is representative of eight different experiments. PI, propidium iodide. incorporation (fig 1). To learn what fraction of cells go through the resting $(G 0 / G 1)$, mitotic $(G 2 / M)$, and division (M) phases, we performed a cytometric LPT cycle analysis in response to anti-CD2 and anti-CD3 activation. After three days with CD2 mAb, 14 (2.2)\% of control $\mathrm{T}$ cells had progressed into the $S$ or $\mathrm{G} 2 / \mathrm{M}$ phases (fig 2 ). A significantly greater $(29(3.1) \% ; \mathrm{p}<0.05)$ fraction of CD LPT entered the $S$ and G2/M phases whereas UC cells entered in a number ( 16 $(2.4) \%)$ comparable to control cells. When anti-CD3 was used, the same differential progression into the $\mathrm{S}$ and $\mathrm{G} 2 / \mathrm{M}$ phases was observed, CD LPT having twice as many cells in S and $\mathrm{G} 2 / \mathrm{M}$ phases $(27(2.9) \% ; \mathrm{p}<0.05)$ than control (12 (1.7)\%) and UC LPT (13 (2.9)\%) (fig 2).

\section{Divergent kinetics of CD and UC T cells}

To gain a more dynamic view of how quickly cells cycle, we performed stathmokinetic analysis to determine the time taken to traverse each cycle phase, reach mitosis, and divide. $^{37384243}$ The S phase traverse time of anti CD2 or CD3 activated CD LPT was half of that of control LPT while the $S$ phase time of UC LPT was longer than that of control LPT (table 1). When potential doubling time (Tpot) was calculated based on BrdU incorporation, it took two days for anti-CD2 or CD3 stimulated control LPT to double. In contrast, CD LPT took one day to double $(\mathrm{p}<0.05)$ while UC LPT needed longer than two days (table 1 ).

\section{Differential expression of cell cycle promoters and inhibitors in CD and UC}

Cell cycle progression is controlled by a large number of promoter and inhibitor molecules. ${ }^{20-24}$ Western blot analysis showed that CDK4 and cyclin D3, which transit $\mathrm{T}$ cells through Gl, were comparably expressed in control, CD, and UC LPT (fig 3). However, phosphorylation of Rb, essential for Gl/S transition, ${ }^{44}$ increased remarkably more in CD than control and UC LPT. CD LPT also showed strong upregulation of cyclin A, responsible for S phase transition, whereas levels were similar in control and UC LPT (fig 3). The strong promoter expression in CD LPT persisted when cyclin Bl was examined together with DNA staining to localise its expression within the cycle. In response to anti-CD2, cyclin B1 in the G2/M phase of CD LPT was four times as high as control LPT $(\mathrm{p}<0.05)$ while that of UC LPT was only half $(\mathrm{p}<0.05)$ (fig 4). Similar differences in cyclin Bl expression were noted among control, $\mathrm{CD}$, and UC activated through the $\mathrm{CD} 3$ pathway. Finally, expression of mitosis marker phosphorylated histone $\mathrm{H}^{35}$ was significantly higher in $\mathrm{CD}$ than control LPT while modestly lower in UC (table 1).

We next determined expression levels of the key cell cycle inhibitors. In CD LPT, p21 and p27 levels were lower than those of control and UC LPT in response to anti-CD2 and anti-CD3, respectively (fig 5). Levels of p53, a key negative regulator of mucosal $\mathrm{T}$ cell replication, ${ }^{40}$ were remarkably

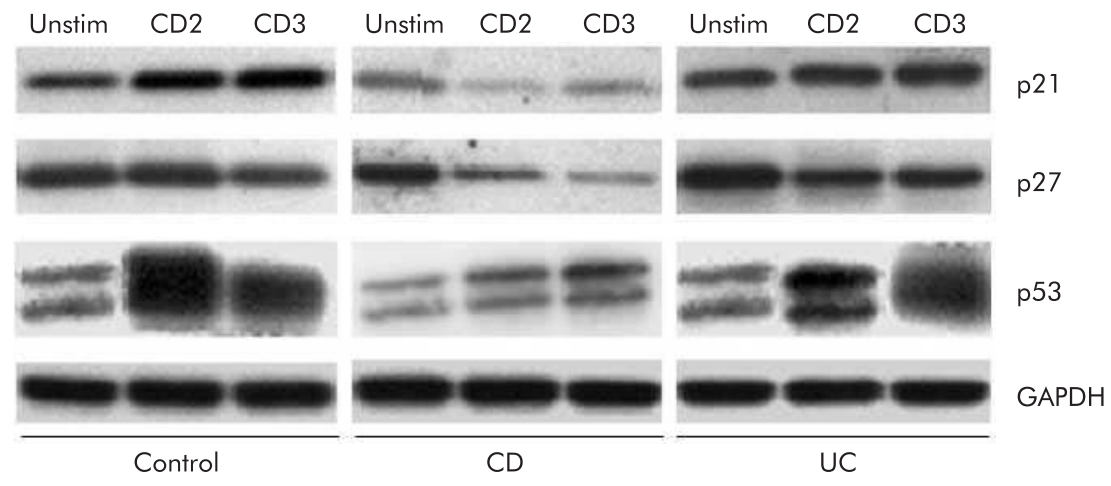

Figure 5 Differential expression of cell cycle inhibitors in control and inflammatory bowel disease mucosal T cells. In Crohn's disease (CD) lamina propria T cells (LPT), levels of p21 and p27 were lower than those of equally stimulated control and ulcerative colitis (UC) LPT. Levels of p53 were markedly lower in CD LPT, particularly when activated through the CD2 pathway, compared with control and UC LPT. Cells were cultured in the absence and presence of anti-CD2 or anti-CD3 for three days, after which expression of cell cycle inhibitors was assessed by western blotting. Each panel is representative of 5-8 different experiments. 


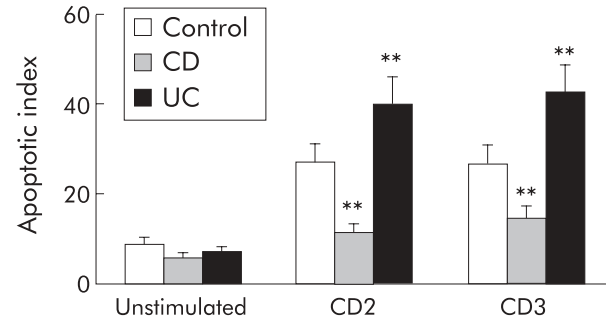

Figure 6 Distinct degrees of apoptosis in control and inflammatory bowel disease mucosal T cells. Crohn's disease (CD) lamina propria T cells (LPT) displayed a decreased degree of activation induced cell death in comparison with control cells while the apoptotic index was significantly higher in ulcerative colitis (UC) than in both CD and control LPT. Cells were cultured in the absence and presence of anti-CD2 or antiCD3 for three days after which apoptosis was assessed by measuring subdiploid DNA content by flow cytometry with propidium iodide staining. Each bar represents mean (SEM) of 6-9 experiments. ${ }^{* *} \mathrm{p}<0.01$ for $C D$ and UC versus control LPT.

lower in CD LPT, particularly when activated through CD2, compared with control and UC LPT (fig 5).

\section{Distinct regulatory mechanisms of $\mathrm{T}$ cell apoptosis in $C D$ and $U C$}

Because CD and UC mucosal T cells display distinct apoptosis patterns, ${ }^{16-18} 46$ and cycling and apoptosis are intimately linked, ${ }^{47-49}$ we studied key apoptosis regulators during $\mathrm{T}$ cell cycling. When control, CD, or UC T cells were stimulated through the $\mathrm{CD} 2$ or $\mathrm{CD} 3$ pathways, apoptosis increased in all groups, but significantly less in CD than in control LPT $(\mathrm{p}<0.01)$, and UC LPT displayed greater apoptosis than both control and CD LPT $(\mathrm{p}<0.05)$ (fig 6).

Caspase 3 and 6, but not caspase 2 and 8, were significantly lower in $\mathrm{CD} 2$ or $\mathrm{CD} 3$ activated $\mathrm{CD}$ than in control LPT $(\mathrm{p}<0.05)$ (fig 7). On the contrary, in UC LPT, the activity of caspase 3 and 6 was significantly higher than in control and CD LPT $(\mathrm{p}<0.05)$ (fig 7). Caspase 1, 4, 5, and 9 activity remained unchanged in all three groups (not shown). We also measured levels of FLIP which, through its long and short forms, prevents apoptosis. ${ }^{50}{ }^{51}$ While FLIP long ( $55 \mathrm{kDa}$ ) expression showed little variation among control, CD, and UC cells, FLIP short $(28 \mathrm{kDa})$ was clearly stronger in CD compared with control and UC LPT (fig 8).

An additional apoptosis regulatory mechanism is preservation of telomere length by telomerase, which controls the replicative potential and lifespan of T cells. ${ }^{29}{ }^{30}$ Control LPT upregulated telomerase activity comparably in response to anti-CD2 or anti-CD3 activation $(\mathrm{p}<0.05)$ (fig 9). In close agreement with their increased and decreased proliferation, respectively, telomerase activity was significantly higher in CD LPT after both anti-CD2 and anti-CD3 stimulation $(\mathrm{p}<0.005$ and $\mathrm{p}<0.05$, respectively) while, strikingly, UC LPT cells totally failed to activate telomerase (fig 9).

\section{Different expansion patterns of CD and UC T cells}

Finally, to assess the intrinsic capacity of $\mathrm{T}$ cells to divide and expand in response to activation, we determined the number of cell divisions in CFDA labelled LPT by measuring its dilution in successive daughter populations. After CD2+CD28 stimulation, three cell divisions comprising 50\% of the original population were seen in control LPT (fig 10). In contrast, $>85 \%$ of CD LPT expanded and generated four daughter cell populations. In UC LPT, $40 \%$ of cells expanded but generating only one daughter cell population (fig 10). When CD3+CD28 antibodies were used, control LPT generated three small daughter cell populations comprising $30 \%$ of the cells. When IBD cells were examined, CD and UC LPT responded with a pattern essentially identical to that of antiCD2+CD28 stimulation (fig 10).

\section{Cell cycle characteristics and clinical parameters}

No significant correlations were found between any of the cell cycle abnormalities detected in CD or UC LPT and the type of therapy (immunosuppressants or non-specific therapy) that IBD patients were receiving at the time of resection. Likewise, age, sex, clinical activity, and diagnosis of control patients (malignant $v$ benign disease) showed no correlation with any of the cell cycle measurements.

\section{DISCUSSION}

To maintain intestinal immune homeostasis, the function of mucosal $\mathrm{T}$ cells is tightly regulated, and cell cycling is essential to generate effector T cells and induce tolerance. ${ }^{52}$ Therefore, when tolerance is lost as in IBD, inflammation may result from dysregulation of the cell cycle. ${ }^{20}$

When the distribution of LPT within the cell cycle was analysed, fewer UC and control cells progressed into the $S$ and $\mathrm{G} 2 / \mathrm{M}$ phases while a larger fraction of $\mathrm{CD}$ did so, probably explaining the high proliferation of mucosal $\mathrm{T}$ cells in this condition. ${ }^{3}$ Although the CD2 activation pathway is dominant in mucosal $\mathrm{T}$ cells, ${ }^{53}$ the fact that more $\mathrm{CD} \mathrm{T}$ cells entered the cell cycle even after CD3 receptor indicates that increased proliferation is receptor independent and perhaps intrinsic to this form of IBD.

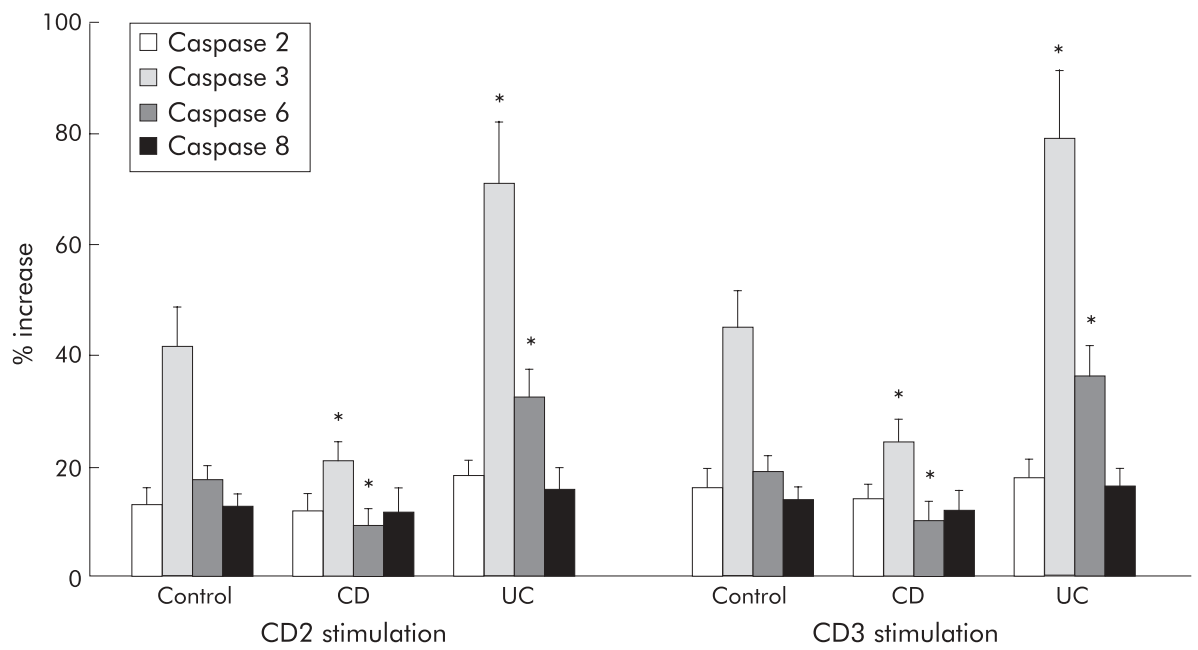

Figure 7 Different caspase activity in control and inflammatory bowel disease mucosal T cells. Compared with control, Crohn's disease (CD) lamina propria T cells (LPT) displayed significantly decreased caspase 3 and 6 activity. In contrast, caspase 3 and 6 activity was significantly higher in ulcerative colitis (UC) than in both control and CD LPT. Cells were cultured in the absence and presence of antiCD2 or anti-CD3 for three days after which caspase activity was measured by a fluorogenic substrate assay. Each bar represents mean (SEM) of 6-9 experiments. ${ }^{*} \mathrm{p}<0.05$ for $\mathrm{CD}$ and UC versus control LPT. 

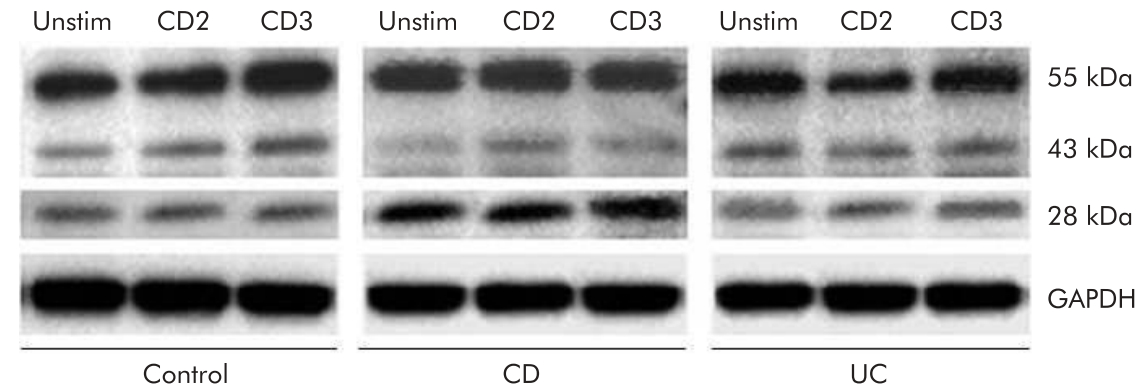

Figure 8 FLIP levels in control and inflammatory bowel disease mucosal T cells. FLIP long ( $55 \mathrm{kDa}$ ) expression levels were essentially the same as those of the control, Crohn's disease (CD), and ulcerative colitis (UC) cells while levels of FLIP short (28 kDa) were clearly higher in CD compared with control and UC lamina propria T cells. Cells were cultured in the absence and presence of anti-CD2 or anti-CD3 for three days, after which expression of FLIP long and short was assessed by western blotting. Each panel is representative of 4-6 different experiments.

Knowing the time spent in each cycle phase translates how quickly a cell reaches mitosis and divides, ${ }^{54}$ and even minimal changes may result in dramatic differences when iterated over many cell divisions. ${ }^{55}{ }^{56} \mathrm{CD}$ T cells spent 12 and 17 hours less in $S$ phase than control and UC cells, respectively, and required only half of the time of control $\mathrm{T}$ cells to complete a cycle. These differences could be intrinsic to CD, and explain why the mucosa of CD patients contains an excess of T cells even during clinical remission. ${ }^{57}$ Cell cycle progression also regulates $\mathrm{T}$ cell cytokine repertoires. ${ }^{19559}$ Shorter cell cycles generate more IFN $-\gamma^{60}$ and this may be a reason why T cell IFN- $\gamma$ production is increased in CD but not in UC. ${ }^{8}$

Congruent with similar Gl traverse times, expression of cyclin D3 and CDK4 was comparable in control, CD, and UC LPT, indicating that G0/Gl phase regulation is not altered in IBD. In contrast, phosphorylation of $\mathrm{Rb}$, needed to pass the restriction point and bring cells into the $\mathrm{S}$ phase, ${ }^{44}$ was remarkably strong in anti-CD2 and anti-CD3 stimulated CD LPT. This indicates a vigorous Gl/S phase transition, as do upregulation of cyclin A and B. In UC, upregulation of these promoters was not observed, as expected by the slower traverse and longer doubling times. Anergic $\mathrm{T}$ cells are arrested in $\mathrm{Gl}$, fail to progress to the $\mathrm{S}$ phase, express low promoter levels, and lack $\mathrm{Rb}$ phosphorylation. ${ }^{61}$ The exact opposite occurs in $\mathrm{CD} T$ cells which quickly traverse the S phase and hyperphosphorylate $\mathrm{Rb}$, translating an unrestrained proliferation and a hyperreactive state.

Levels of p53 phosphorylation were remarkably low in CD $\mathrm{T}$ cells, regardless of how activated. P53 mediates cell cycle arrest, ${ }^{25} 27$ and is a pivotal negative regulator of intestinal

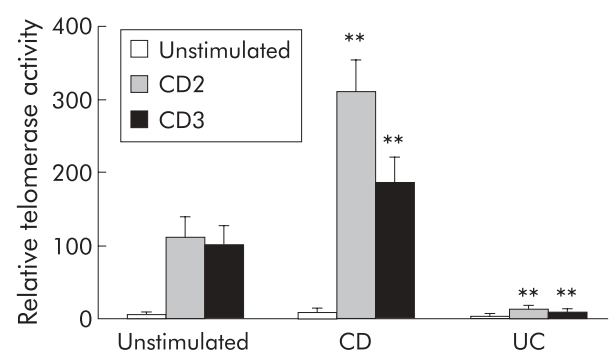

Figure 9 Distinct telomerase activity of control and inflammatory bowel disease mucosal T cells. Telomerase activity was significantly higher in Crohn's disease (CD) than control lamina propria T cells (LPT), while absent in equally stimulated ulcerative colitis (UC) LPT. Cells were cultured in the absence and presence of anti-CD2 or anti-CD3 for three days after which cells were lysed, their DNA amplified, and analysed using the telomeric repeat amplification protocol (TRAP) protocol. Each bar represents mean (SEM) of 5-8 experiments. ${ }^{* *} \mathrm{p}<0.005$ for CD and UC versus control LPT. immunity by delaying mucosal T cell cycling. ${ }^{40}$ Thus low p53 and p21 levels in CD could remove a break that prevents excessive proliferation ${ }^{27}$ and contribute to mucosal $\mathrm{T}$ cell hyperreactivity. Increased cycling can break tolerance and cause autoimmunity, ${ }^{20}$ and the combination of weak inhibitor and strong promoter levels coupled to rapid cycling define a profile compatible with loss of tolerance in CD. In UC, levels of promoters and inhibitors were essentially normal but, in the face of active inflammation, normal levels may be inappropriate and reflect a state of anergy in this condition.

Resting $\mathrm{T}$ cells are resistant to apoptosis ${ }^{62}$ and must enter the $S$ phase to become susceptible to cell death. ${ }^{47} \mathrm{CD} 2$ and CD3 activated CD cells displayed a decreased and UC cells an increased apoptotic index compared with controls, and the activity of caspase 3 and 6 was low in CD but high in UC, matching with the respective levels of apoptosis in each form of IBD. Moreover, FLIP short, a specific inhibitor of caspase 8 and activation induced apoptosis, ${ }^{51}{ }^{63}$ was higher in CD than in control and UC LPT. While the decreased caspase activity and increased short FLIP could explain the diminished apoptosis of CD T cells, ${ }^{16-18}$ their faster cell cycle contrasts

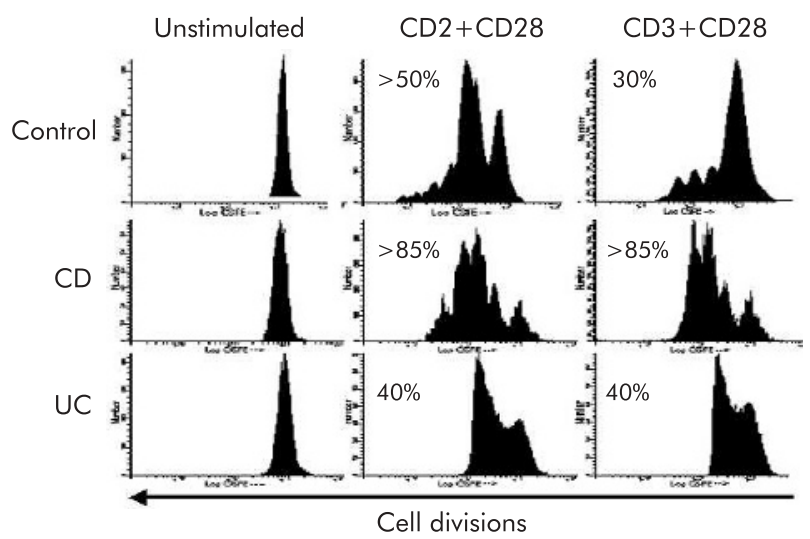

Figure 10 Distinct cellular expansion capacity of control and inflammatory bowel disease mucosal T cells. The number of cells expanding in response to anti-CD2+anti-CD28 or anti-CD3+anti-CD28 activation was greater in Crohn's disease (CD) than control lamina propria T cells (LPT) while ulcerative colitis (UC) LPT divided only once. Cells were incubated with $5 \mu \mathrm{M}$ carboxyfluorescein diacetate and cultured in the absence and presence of interleukin 2 with anti$C D 2+$ anti-CD28 or anti-CD3+anti-CD28 for four days, and the number of cell divisions determined by flow cytometry. The first peak to the right represents the undivided cell population. The numbers indicate the percentage of divided cells distributed in the subsequent peaks. The figure is representative of seven different experiments. 
with the observation that cells become more susceptible to cell death when actively cycling. ${ }^{25} 4762$ This discrepancy suggests that the balance between cell cycling and death is lost in $\mathrm{CD}$, resulting in unrestrained proliferation due, at least in part, to defective apoptosis.

Lifespan is controlled by multiple factors, among which telomerase, a unique RNA dependent DNA polymerase, plays a central role by elongating telomeres and preserving lymphocyte ability to replicate and survive. ${ }^{64}$ Telomerase activity was significantly higher in CD LPT, possibly resulting in an excessive number of daughter cell populations that contribute to enhanced proliferation and survival. Compatible with their decreased lifespan, telomerase activity was conspicuously absent in UC LPT. This dichotomy is surprising because $\mathrm{T}$ cells from chronically inflamed sites, like IBD mucosa, should contain high telomerase levels. ${ }^{65}$ Nevertheless, UC $\mathrm{T}$ cells lack telomerase activity, like in HIV-1 infection and aging, conditions characterised by premature and physiological immune senescence, respectively. ${ }^{66}$ Both conditions are typically associated with anergy, reinforcing the concept that mucosal T cells may be anergic in UC. A possible explanation includes a systemic defect, backed by genomic instability and high frequency of telomeric associations in circulating lymphocytes of UC patients. ${ }^{67}$

Additional striking differences were detected when LPT division was analysed by CFDA staining. Regardless of CD2 or CD3 activation, CD LPT vigorously expanded while T cell division was drastically restricted in UC, with less than half of the cells dividing. These results are in full agreement with differences in cell cycling, cell cycle regulators, apoptosis, and telomerase activity, and a pattern of tyrosine hyper- and hypophosphorylation in CD and UC, respectively (B RiveraReyes, work in progress). Together, these result strongly corroborate the concept of $\mathrm{T}$ cell hyper- and hyporeactivity in $\mathrm{CD}$ and $\mathrm{UC}$, respectively. In fact, cells that divide and progress through the cell cycle mediate an effective immune response and prevent anergy, while those that fail to divide on receptor engagement lead to anergy. ${ }^{19} 525859$ Hyporesponsiveness in UC cannot be simply attributed to chronic stimulation and an altered redox state, as proposed for rheumatoid synovial $\mathrm{T}$ cells, ${ }^{68}$ because $\mathrm{T}$ cells in CD are also exposed to comparably high levels of reactive oxygen species. ${ }^{69} 70$

In conclusion, compared with normal mucosal T cells, CD and UC cells display unique cell cycle profiles controlled by distinct regulatory mechanisms. The lack of correlation with any clinical parameter suggest that the cell cycle abnormalities detected in CD and UC may be intrinsic to each form of IBD. Because the cell cycle controls $\mathrm{T}$ cell function in immunity, tolerance, and autoimmunity, ${ }^{20}$ the distinct abnormalities of $\mathrm{CD}$ and $\mathrm{UC}$ indicate opposite $\mathrm{T}$ cell dependent pathogenic capacities. Intervening on specific molecular defects of $\mathrm{T}$ cell function, such as resistance to apoptosis in $\mathrm{CD}$, has been shown to be therapeutically effective. ${ }^{71}$ Accordingly, identification of cell cycle regulatory abnormalities unique to CD or UC may also lead to novel therapeutic strategies specific for each form of IBD.

\section{ACKNOWLEDGMENTS}

We thank Michael Sramkoski, Megan Gottlieb, and Xia Xi for technical assistance. We also thank the Departments of Surgery and Pathology, University Hospitals of Cleveland, and the Colorectal Surgery Department of the Cleveland Clinic Foundation, Cleveland, Ohio. Some tissue samples were provided by the Cooperative Human Tissue Procurement Facility of University Hospitals of Cleveland. This work was supported by grants from the National Institutes of Health (DK30399 and DK50984 to CF), the Deutsche Forschungsgemeinschaft and the Charité Berlin, Germany (STU247/2-1 and 247/3-1 to AS), the National Cancer Institute (CA73413 and CA43703 to JWJ), and the Juvenile Diabetes Research Foundation International (2-2000-390 to SM).

\section{Authors' affiliations}

A Sturm, Division of Gastroenterology, Department of Medicine, University Hospitals of Cleveland, Case Western Reserve University School of Medicine, Cleveland, Ohio, USA, and Department of Medicine, Division of Gastroenterology and Hepatology, CharitéUniversitätsmedizin Berlin, Campus Virchow Clinic, Berlin, Germany A Z A Leite, S Danese, K A Krivacic, G A West, C Fiocchi, Division of Gastroenterology, Department of Medicine, University Hospitals of Cleveland, Case Western Reserve University School of Medicine, Cleveland, Ohio, USA

S Mohr, Division of Endocrinology, Department of Medicine, University Hospitals of Cleveland, Case Western Reserve University School of Medicine, Cleveland, Ohio, USA

J W Jacobberger, Ireland Cancer Research Center, University Hospitals of Cleveland, Case Western Reserve University School of Medicine, Cleveland, Ohio, USA

\section{REFERENCES}

1 Fiocchi C. Inflammatory bowel disease: etiology and pathogenesis. Gastroenterology 1998;115:182-205.

2 Lawrance IC, Fiocchi C, Chakravarti S. Ulcerative colitis and Crohn's disease: distinctive gene expression profiles and novel susceptibility candidate genes. Hum Mol Genet 2001;10:445-56.

3 Kugathasan S, Willis J, Dahms BB, et al. Intrinsic hyperreactivity of mucosal T cells to interleukin-2 in pediatric Crohn's disease. J Pediatr 1998;133:675-81

4 Matsuura T, West GA, Klein JS, et al. Soluble interleukin 2 and CD8 and CD4 receptors in inflammatory bowel disease. Gastroenterology 1992; 102:2006-14.

5 Kusugami K, Youngman KR, West GA, et al. Intestinal immune reactivity to interleukin 2 differs among Crohn's disease, ulcerative colitis, and controls. Gastroenterology 1989;97:1-9.

6 Fiocchi C, Hilfiker ML, Youngman KR, et al. Interleukin 2 activity of human intestinal mucosa mononuclear cells. Decreased levels in inflammatory bowel disease. Gastroenterology 1984;86:734-42.

7 Mullin GE, Lazenby A, Harris ML. Increased interleukin-2 messenger RNA in the intestinal mucosal lesion of Crohn's disease but not ulcerative colitis. Gastroenterology 1992;102:1620-7.

8 Fais S, Capobianchi MR, Pallone F, et al. Spontaneous release of interferon gamma by intestinal lamina propria lymphocytes in Crohn's disease. Kinetics of in vitro response to interferon gamma inducers. Gut 1991;32:403-7.

9 Fuss IJ, Neurath M, Boirivant M, et al. Disparate CD4+ lamina propria (LP) lymphokine secretion profiles in inflammatory bowel disease. Crohn's disease LP cells manifest increased secretion of IFN-gamma, whereas ulcerative colitis LP cells manifest increased secretion of IL-5. J Immunol 1996;157:1261-70.

10 Monteleone G, MacDonald TT, Wathen NC, et al. Enhancing lamina propria Th1 cell responses with interleukin 12 produces severe tissue injury. Gastroenterology 1999; 117:1069-77.

11 Parronchi P, Romagnani P, Annunziato F, et al. Type 1 T-helper cell predominance and interleukin-12 expression in the gut of patients with Crohn's disease. Am J Pathol 1997;150:823-32.

12 Monteleone G, Trapasso F, Parrello T, et al. Bioactive IL-18 expression is upregulated in Crohn's disease. J Immunol 1999;163:143-7.

13 Pizarro TT, Michie MH, Bentz $M$, et al. IL-18, a novel immunoregulatory cytokine, is up-regulated in Crohn's disease: expression and localization in intestinal mucosal cells. J Immunol 1999;162:6829-35.

14 Matsuura T, West GA, Levine AD, et al. Selective resistance of mucosal T-cell activation to immunosuppression in Crohn's disease. Dig Liver Dis 2000;32:484-94

15 Ueyama H, Kiyohara T, Sawada N, et al. High Fas ligand expression on lymphocytes in lesions of ulcerative colitis. Gut 1998;43:48-55.

16 Ina K, ltoh J, Fukushima K, et al. Resistance of Crohn's disease T cells to multiple apoptotic signals is associated with a $\mathrm{Bcl}-2 / \mathrm{Bax}$ mucosal imbalance. $J$ Immunol 1999; 163:1081-90.

17 Boirivant M, Marini M, Di Felice G, et al. Lamina propria T cells in Crohn's disease and other gastrointestinal inflammation show defective CD2 pathwayinduced apoptosis. Gastroenterology 1999;116:557-65.

18 Itoh J, de la Motte C, Strong SA, et al. Decreased Bax expression by mucosal T cells favours resistance to apoptosis in Crohn's disease. Gut 2001;49:35-41.

19 Bird JJ, Brown DR, Mullen AC, et al. Helper T cell differentiation is controlled by the cell cycle. Immunity 1998;9:229-37.

20 Balomenos D, Martinez A. Cell-cycle regulation in immunity, tolerance and autoimmunity. Immunol Today 2000;21:551-5.

21 Grana X, Reddy EP. Cell cycle control in mammalian cells: role of cyclins, cyclin dependent kinases (CDKs), growth suppressor genes and cyclindependent kinase inhibitors (CKIs). Oncogene 1995; 1 1:211-19.

22 Sherr CJ. G1 phase progression: cycling on cue. Cell 1994;79:551-5.

23 Sherr CJ, Roberts JM. Inhibitors of mammalian G1 cyclin-dependent kinases. Genes Dev 1995;9:1149-63.

24 Sherr CJ, Roberts JM. CDK inhibitors: positive and negative regulators of G1phase progression. Genes Dev 1999;13:1501-12.

25 Lenardo MJ. The molecular regulation of lymphocyte apoptosis. Semin Immunol 1997;9:1-5.

26 Green DR, Schuler M. T cell development: some cells get all the breaks. Nat Immunol 2000;1:15-17. 
27 Levine AJ. p53, the cellular gatekeeper for growth and division. Cell 1997;88:323-31.

28 Hengartner MO. The biochemistry of apoptosis. Nature 2000;407:770-6.

29 Hodes RJ. Telomere length, aging, and somatic cell turnover. J Exp Med 1999; 190:153-6.

30 Buys CH. Telomeres, telomerase, and cancer. N Engl J Med 2000;342: 1282-3.

31 Klein JR. Advances in intestinal T-cell development and function. Immunol Today 1995; 16:322-24.

32 Duchmann R, Kaiser I, Hermann E, et al. Tolerance exists towards resident intestinal flora but is broken in active inflammatory bowel disease (IBD). Clin Exp Immunol 1995; 102:448-55

33 Duchmann R, Neurath MF, Meyer zum Buschenfelde KH. Responses to self and non-self intestinal microflora in health and inflammatory bowel disease. Res Immunol 1997;148:589-94.

34 Duchmann R, Schmitt E, Knolle P, et al. Tolerance towards resident intestinal flora in mice is abrogated in experimental colitis and restored by treatment with interleukin-10 or antibodies to interleukin-12. Eur J Immunol 1996;26:934-8.

35 West GA, Matsuura T, Levine AD, et al. Interleukin 4 in inflammatory bowel disease and mucosal immune reactivity. Gastroenterology 1996; 110:1683-95

36 Jacobberger JW, Sramkoski RM, Wormsley SB, et al. Estimation of kinetic cell-cycle-related gene expression in $\mathrm{G} 1$ and $\mathrm{G} 2$ phases from immunofluorescence flow cytometry data. Cytometry 1999;35:284-9.

37 Begg AC, McNally NJ, Shrieve DC, et al. A method to measure the duration of DNa synthesis and the potential doubling time from a single sample. Cytometry 1985:6:620-6.

38 White RA, Meistrich ML, Pollack A, et al. Simultaneous estmation of of $T(G 2+M), T(S)$, and $T$ (pot) using single sample dynamic tumor data from bivariate DNA-thymidine analogue cytometry. Cytometry 2000;41:1-8.

39 Mohr S, McCormick TS, Lapetina EG. Macrophages resistant to endogenously generated nitric oxide-mediated apoptosis are hypersensitive to exogenously added donors: dichotomous apoptotoc response independent of caspase 3 and reversal by the mitogen-activated protein kinase kinase (MEK) inhibitor PD098059. Proc Natl Acad Sci U S A 1998;95:5054-61.

40 Sturm A, Itoh J, Jacobberger JW, et al. p53 negatively regulates intestinal immunity by delaying mucosal T cell cycling. J Clin Invest 2002;109:1481-92.

$41 \mathrm{Kim}$ NW, Wu F. Advances in quantification and characterization of telomerase activity by the telomeric repeat amplification protocol (TRAP). Nucleic Acids Res 1997;25:2595-7.

42 Sramkoski RM, Wormsley SW, Bolton WE, et al. Simultaneous detection of cyclin B1, p105, and DNA content provides complete cell cycle phase fraction analysis of cells that endoreduplicate. Cytometry 1999;35:274-83.

43 Bonhoeffer S, Mohri H, Ho D, et al. Quantification of cell turnover kinetics using 5-bromo-2'-deoxyuridine. J Immunol 2002; 164:5049-54.

44 Weinberg RA. The retinoblastoma protein and cell cycle control. Cytometry 1995;81:323-30

45 Wei Y, Yu L, Bowen J, et al. Phosphorylation of histone H3 is required for proper chromosome condensation and segregation. Cell 1999;97:99-109.

46 Levine AD. Apoptosis: implications for inflammatory bowel disease. Inflamm Bowel Dis 2000:6:191-205.

47 Boehme SA, Lenardo MJ. Propriocidal apoptosis of mature T lymphocytes occurs at S phase of the cell cycle. Eur J Immunol 1993;23:1552-60.

48 King KL, Cidlowski JA. Cell cycle and apoptosis: common pathways to life and death. J Cell Biochem 1995;58:175-80.

49 Vaux DL, Korsmeyer SJ. Cell death in development. Cell 1999;96:245-54

50 Scaffidi C, Schmitz I, Krammer PH, et al. The role of c-FLIP in modulation of CD95-induced apoptosis. J Biol Chem 1999;274:1541-8.
51 Kataoka T, Budd RC, Holler N, et al. The caspase-8 inhibitor FLIP promotes activation of $\mathrm{nF}-\mathrm{kappaB}$ and erk signaling pathways. Curr Biol 2000;10:640-8.

52 Wells AD, Walsh MC, Sankaran D, et al. T cell effector function and anergy avoidance are quantitatively linked to cell division. J Immunol 2000; 165:2432-43.

53 Targan SR, Deem RL, Liu M, et al. Definition of a lamina propria T cell responsive state. Enhanced cytokine responsiveness of T cells stimulated through the CD2 pathway. J Immunol 1995:154:664-75.

54 Juan G, Traganos F, James WM, et al. Histone H3 phosphorylation and expression of cyclins $A$ and $B 1$ measured in individual cells during their progression through G2 and mitosis. Cytometry 1998;32:71-7.

55 Germain RN. The art of the probable: system control in the adaptive immune system. Science $2001 ; 293: 240-5$.

56 www.sciencemag.org/cgi/content/full/293/5528/240/DC1.

57 Modigliani R, Mary JY, Simon JF, et al. Clinical, biological, and endoscopic picture of attacks of Crohn's disease. Evolution on prednisolone. Gastroenterology 1990;98:811-18.

58 Richter A, Lohning M, Radbruch A. Instruction for cytokine expression in T helper lymphocytes in relation to proliferation and cell cycle progression. J Exp Med 1999;190:1439-50.

59 Gett AV, Hodgkin PD. Cell division regulates the T cell cytokine repertoire, revealing a mechanism underlying immune class regulation. Proc Natl Acad Sci U S A 1998;95:9488-93.

60 Jonuleit $H$, Schmitt $E$, Stassen $M$, et al. Identification and functional characterization of human CD4(+)CD25(+) T cells with regulatory properties isolated from peripheral blood. J Exp Med 2001;193:1285-94.

61 Boussiotis VA, Chen ZM, Zeller JC, et al. Altered T-cell receptor + CD28mediated signaling and blocked cell cycle progression in interleukin 10 and transforming growth factor-beta-treated alloreactive $T$ cells that do not induce graft-versus-host disease. Blood $2001 ; 97: 565-71$.

62 Kabelitz D, Pohl T, Pechhold K. Activation-induced cell death (apoptosis) of mature peripheral T lymphocytes. Immunol Today 1993; 14:338-39.

63 Thome M, Schneider P, Hofmann K, et al. Viral FLICE-inhibitory proteins (FLIPs) prevent apoptosis induced by death receptors. Nature 1997;386:517-21.

64 Blasco MA, Funk W, Villeponteau B, et al. Functional characterization and developmental regulation of mouse telomerase RNA. Science 1995;269:1267-70.

65 Hodes RJ, Hathcock KS, Weng NP. Telomeres in T and B cells. Nat Rev Immunol 2002;2:699-706.

66 Appay V, Rowland-Jones SL. Premature ageing of the immune system: the cause of AIDS? Trends Immunol 2002;23:580-5.

67 Cottliar A, Fundia A, Boerr L, et al. High frequencies of telomeric associations, chromosome aberrations, and sister chromatid exchanges in ulcerative colitis. Am J Gastroenterol 2000;95:2301-7.

68 Maurice MM, Nakamura $\mathrm{H}$, van der Voort EA, et al. Evidence for the role of an altered redox state in hyporesponsiveness of synovial T cells in rheumatoid arthritis. J Immunol 1997; 158:1458-65.

69 Simmonds NJ, Allen RE, Stevens TR, et al. Chemiluminescence assay of mucosal reactive oxygen metabolites in inflammatory bowel disease. Gastroenterology 1992;103:186-96.

70 Dijkstra G, Moshage H, van Dullemen HM, et al. Expression of nitric oxide synthases and formation of nitrotyrosine and reactive oxygen species in inflammatory bowel disease. J Pathol 1998;186:416-21.

71 ten Hove T, van Montfrans C, Peppelenbosch MP, et al. Infliximab treatment induces apoptosis of lamina propria T lymphocytes in Crohn's disease. Gut 2002;50:206-11

\section{EDITOR'S QUIZ: GI SNAPSHOT}

\section{Answer}

From question on page 1589

At prior laparotomy, multiple skipped longitudinal ulcers causing perforation and stenosis were identified in the ileum. Crohn's disease was then diagnosed. Biopsies of the gastric "bamboo trees" demonstrated non-caseating granulomas by serial sections. Gastric involvement in Crohn's disease seemed rare with classical endoscopic findings, including granular mucosa, aphthoid erosions, and linear ulcers but recent studies have indicated a higher incidence of involvement than previously speculated. Endoscopic findings characterised by swollen longitudinal folds transversed by erosive fissures or linear furrows has been termed "bamboo joint-like appearance" of the gastric body and cardia. This unique finding is quite specific for Crohn's disease and can be found in half of patients if examined carefully using endoscopic dyes. Focal gastritis is also common in Crohn's disease and may be helpful in the differential diagnosis of indeterminate colitis. Our patient had suffered from relapsing symptoms despite treatment with sulphasalazine and elemental diet. 